\title{
Adolescent Girls' Evaluation of Brands during Liminal Life Stages
}

\author{
Dong Dong and Kara Chan
}

\begin{abstract}
Liminality denotes the sense of moving from one life stage to another. A well-known liminal period for identity construction is the teenage years. A survey study was conducted to examine the concept of liminality and its influence on adolescents' relationships with global brands. Altogether 603 adolescent girls in Hong Kong and Shanghai completed a questionnaire with questions on female gender role perception and attitudes toward six global brands. Liminal life stages of adolescence, proxied by year in school, emerged as a stronger predictor of brand evaluations than cultural background, socioeconomic status or the girls' perceptions about female gender roles. The findings support the homogenization of consumer culture within the context of globalization.
\end{abstract}

Index Terms-Liminality, adolescents, consumer-brand bonds, brand evaluation, global brands.

\section{INTRODUCTION}

Everyone's life involves various stages, which are usually indexed by age. As one of the most primary and universal demographic parameters in consumer studies, age, however, should not be understood from a chronological perspective only [1]. In this research, life stages are constructed and investigated from an anthropological perspective. It is argued that age differences are signified by rites of passage, rites that assign different roles and allocate different resources to our lives [2]. For example, the passages from infant to toddler, from tweenage to teenage, from childhood to adulthood, all exhibit a lifelong pattern of identity exploration [3]-[5].

More specifically, the concept of liminality is used to indicate the "ambiguity and paradox" [6] of a transitional life stage that people experience. Liminality denotes the sense of being "betwixt and between" [6], [7]. A person is in the transition from one role to another [8]. A well-known liminal period for identity construction is the teenage years. Many regard the teens as a time full of tension between self and society that is intensified and lessened by continued role experimentation [9].

How, then, do such liminal stages interplay with teenagers' roles as consumers? Research on adolescent consumption has blossomed since the mid-1970s [10]. Scholars have then argued that their consumption patterns may change during the transitional periods of their lives, such as from tweens to teens [11]-[14]. The patterns may also be influenced by the

Manuscript received October 1, 2013; revised March 27, 2014. This work was supported by the David C. Lam Institute for East-West Studies, Hong Kong Baptist University.

Dong Dong is with David C. Lam Institute for East-West Studies, Hong Kong Baptist University, Hong Kong (e-mail: dongdong@hkbu.edu.hk).

Kara Chan is with the Department of Communication Studies, Hong Kong Baptist University, Hong Kong (e-mail: karachan@hkbu.edu.hk). social contexts in which they live [15]. This research therefore had two objectives. The first was to demonstrate the significance of adolescent liminality in defining teenagers' roles as consumers. The second was to compare the importance of adolescent liminality with other social, economic, and cultural variables in determining adolescents' brand evaluations.

\section{LITERATURE REVIEW}

\section{A. Liminal Consumption among the Young Consumers}

Liminality, an anthropological term, means threshold. In a liminal stage people can experience detachment from previously accepted roles and social structures without having yet acquired the attributes of a future state [8]. For example, the transition from girlhood to womanhood is a period during which "personal identities are suspended" and "significant psychological consequences" ensue [8].

Scholars today have begun to recognize the utility of the concept of liminality for explaining their observations of young consumers [12]-[14], [16]. Studies have illustrated how children mediate their liminal status with good ownership and other consumption practices in the context of global consumerism. [16], for example, reviewed the history of commercialization and sexualization of the images of preteen girls in the American mass media and the fashion market. They discovered that it is particularly difficult to construct and maintain preteen girls as an age-delineated marketing category since they cannot be simply acculturated into the sexual personae as the market anticipated. Rather, blurring of the age identity boundaries for young girls has allowed them to appropriate various cultural models of girlhood and experiment with sexuality, race, ethnicity and class. This has created an ambiguous and dynamic space in which they can act out trial identities.

\section{B. Liminal Status and Self-Brand Relations}

The significance of consumer-brand relation has been observed among young consumers [17]. A greater understanding of the self, together with social pressures to 'fit in' a symbolic group encourages adolescents to own certain brands [17]. Studies have demonstrated that many individuals use brands as symbolic resources to create and communicate their identities [18] through both lived and mediated channels [19]. Such symbolic consumption also helps consumers to establish and exhibit themselves as members of certain cultural categories such as gender and class, and adherents of certain value systems [19]. As McCracken [20], [21] has remarked, brands have value because they add value, and they add value because they add 
meaning. The meaning transfers between brands and consumers through lived and mediated experiences often become more sophisticated during the process of socialization [22]-[24]. Adolescence is a period when socialization is intense and also one of the critical periods when consumers often become very sensitive to certain brands and develop deep meanings attached to them [25].

Research on the relationship between adolescents and consumer brands indicates great potential for developing a theory of liminal consumption, but there are two major problems. First, the "structural simplicity" [7] of the concept of liminality makes it difficult to use it to characterize adequately the culturally complex phenomenon of adolescent brand preferences. The liminal status of adolescents is often compounded by other factors, such as gender, cultural, and socioeconomic variations, which may result in very different brand-related behaviors. Second, even though some previous studies have applied liminality as a theoretical lens, they focused on the micro-level, using qualitative research methods such as personal diaries, accompanied shopping trips, and in-depth interviews. Much less is known about the social structures and the cultural values adolescents encounter and the influence of encountering them during liminal periods.

This research was designed to address these two problems. It applied quantitative survey research to explore the significance of liminality in adolescents' brand evaluations. More specifically, it asked: how does the sense of liminality make itself salient when adolescences' brand evaluations interact with social structures such as socioeconomic status, gender roles and social values?

\section{MEthodS}

\section{A. Questionnaire and Sample}

Adolescent girls were surveyed in Hong Kong and Shanghai, two cosmopolitan cities that share a lot of cultural similarities. The questionnaires used in Hong Kong and Shanghai were almost identical and were both phrased in Chinese. A convenience sample of female students was drawn in each city. In the Hong Kong survey, the questionnaire distributors, who were students from a local public university, were asked to recruit female secondary school students via their personal social networks. In Shanghai, five local secondary schools (including one vocational training school) coordinated the survey by having their students complete the questionnaire during a normal class period. The Hong Kong survey was carried out in November 2011 and the Shanghai survey in March 2012. All participation was voluntary and anonymous.

\section{B. Independent Variables}

The independent variables were the location (city), the liminal stages the respondents were experiencing, family economic status, and the respondents' perceptions of female roles.

Location-The cultures of Hong Kong and Shanghai are both regarded as a mixture of the West and the East. Hong Kong, however, still maintains a patriarchic social structure while women in Shanghai seem to suffer less from gender inequality [26], [27]. Economically, Hong Kong is a well-developed region with a notable economic take-off in the 1970s [28] while Shanghai did not start its economic transformation until the 1990s [29].

Liminal stages-In this study, "schooling" was regarded as a critical indicator of different liminal stages that a teenage girl may have experienced. Year in school was therefore chosen as a baseline indicator of adolescent liminal stages. The grade structures of the secondary schools are slightly different in Hong Kong and Shanghai. The former has 7 grades and the latter has 6. Grades secondary 1, 2 and 3 were grouped as "younger teens" and secondary 4, 5, 6 and 7 as "older teens". This facilitated exploring the nuances of the girls' consumption patterns in two liminal periods of adolescence.

Economic status-The respondents' economic status was measured in terms of monthly family income and housing status. Due to the real income differences between the two cities, the variable "family income" was regrouped into "Low", "Middle", and "High" based on the original responses. The housing structures are different in the two cities as well. Therefore the variable "housing status" was regrouped into "Rental" and "Owned" based on the original responses.

Perceptions of female identities-Thirty-six statements about gender roles and social values were used to assess the elements the teenage girls used to construct their identities [30]. The statements were derived from those used in a qualitative study of perceptions of gender roles among girls aged 15 to 18 in Hong Kong [31]. Sample statements included "Females should appreciate their own strengths", "Females who bear children enjoy a complete life" and "Females should not pursue a slim body at all cost". Each statement was evaluated on a 5-point Likert scale ranging from 1 (strongly disagree) to 5 (strongly agree). Principal component analysis (PCA) was employed to reduce the perceptions of female identities to a smaller set for analysis.

\section{Dependent Variables}

Brand evaluations-The respondents' evaluations of "youth brands" and "adult brands" were surveyed. Previous studies have confirmed that children's perceptions of brands change as they mature and develop more sophisticated information processing abilities and skills [32]. Adolescents' reactions at different stages of development would vary when they encounter youths' or adults' brands. The respondents used a 10-point scale (1=dislike a lot, 10=like a lot) to indicate their attitude toward six global brands - Coca Cola, Google, McDonald's, Disney, Apple and Samsung. Coca Cola, McDonald's and Disney were classified as "youth brands" while Google, Apple and Samsung were classified as "adult brands". These brands were selected from the 2011 list of the top 20 global brands [33].

\section{Hypothesis Testing}

Two groups of hypotheses were generated based on this reasoning.

H1a: Teenage girls' evaluations of youth brands can be predicted based on their perceptions of female identity, their liminal stages, and the cultural and economic factors of their 
living environment.

H1b: Teenage girls' evaluations of adult brands can be predicted based on their perceptions of female identity, their liminal stages, and the cultural and economic factors of their living environment.

H2a: The importance of survey location as a predictor of the teenage girls' evaluations of youth brands will diminish as other predictors, especially the liminal stages of adolescence, are taken into account.

$\mathrm{H} 2 \mathrm{~b}$ : The importance of survey location as a predictor of the teenage girls' evaluations of adult brands will diminish as other predictors, especially the liminal stages of adolescence, are taken into account.

\section{RESULtS}

\section{A. Respondents}

The survey questionnaire was completed by 285 teenage girls in Hong Kong and 318 in Shanghai. The respondents were all aged between 13 and 18 and studying in middle school or high schools. The average age was 15.4 (Hong Kong girls 15.5; Shanghai girls 15.3). More than half of the respondents studied at a middle school $(54.4 \%)$ and were regarded as "younger teens"; the rest were high school students $(45.6 \%)$ and regarded as "older teens". Most of the girls were from low or middle class families, based on the reported monthly family incomes. In total, $41.1 \%$ of the reported incomes were categorized as low, $51.2 \%$ as middle, and only $7.7 \%$ as high. Because of the public housing policy in Hong Kong, a much larger proportion of the Hong Kong respondents lived in rental properties than the Shanghai ones (48.1\% versus $13.9 \%)$. Table I summarizes the descriptive characteristics of the respondents.

\begin{tabular}{lccc}
\multicolumn{5}{c}{ TABLE I: PROFILE OF THE RESPONDENTS } \\
& Hong Kong & Shanghai & Total \\
& $(\mathrm{N}=285)$ & $(\mathrm{N}=318)$ & $(\mathrm{N}=603)$ \\
\hline Mean age & 15.5 & 15.3 & 15.4 \\
Liminal stages & & & \\
$\quad \begin{array}{l}\text { Younger teens } \\
\text { Older teens }\end{array}$ & $138(48.4 \%)$ & $190(59.7 \%)$ & $328(54.4 \%)$ \\
Family income & $147(51.6 \%)$ & $128(40.3 \%)$ & $275(45.6 \%)$ \\
$\quad$ & & & \\
Low & $119(41.8 \%)$ & $126(40.5 \%)$ & $245(41.1 \%)$ \\
Hiddle & $138(48.4 \%)$ & $167(53.7 \%)$ & $305(51.2 \%)$ \\
Housing & $28(9.8 \%)$ & $18(5.8 \%)$ & $46(7.7 \%)$ \\
$\quad$ Rental & & & \\
Owned & $125(48.1 \%)$ & $39(13.9 \%)$ & $164(30.4 \%)$ \\
& $135(51.9 \%)$ & $241(86.1 \%)$ & $376(69.6 \%)$ \\
\hline
\end{tabular}

\footnotetext{
Notes:

a. Self-reported. For the Hong Kong sample, "Low" = under HK\$20,000/mo., "Middle" = HK\$20,000-50,000/mo., and "High" = over HK\$50,000/mo. For the Shanghai sample, "Low" = under RMB10,000/mo., "Middle" = RMB10,000-40,000/mo., and "High" = over RMB40,000/mo.
}

\section{B. Perceptions of Female Gender Roles}

A principal component analysis (PCA) was employed to reduce the measured perceptions of female identities to a smaller set of key components. The respondents' evaluations of the 36 statements on gender roles and social values were firstly examined separately in order to assess the stability of the dimensions across the two groups. Variables that had a low correlation with other variables and low loadings on the factors were removed. As a result, 13 perception variables remained. An eigenvalue greater than one was selected as the criterion for determining the number of components to be extracted. The varimax rotation procedure was performed. Four principal components with eigenvalues greater than one accounting for $66.9 \%$ of the total variance were extracted. Cronbach's alpha coefficient for each component ranged from 0.66 to 0.85 , which indicates moderate to high internal reliability for each component. Table II summarizes the results of the analysis. The four types of female identity emerging from the respondents' evaluations were labelled as 1) Be natural, 2) Be modern, 3) Be traditional, and 4) Be responsible.

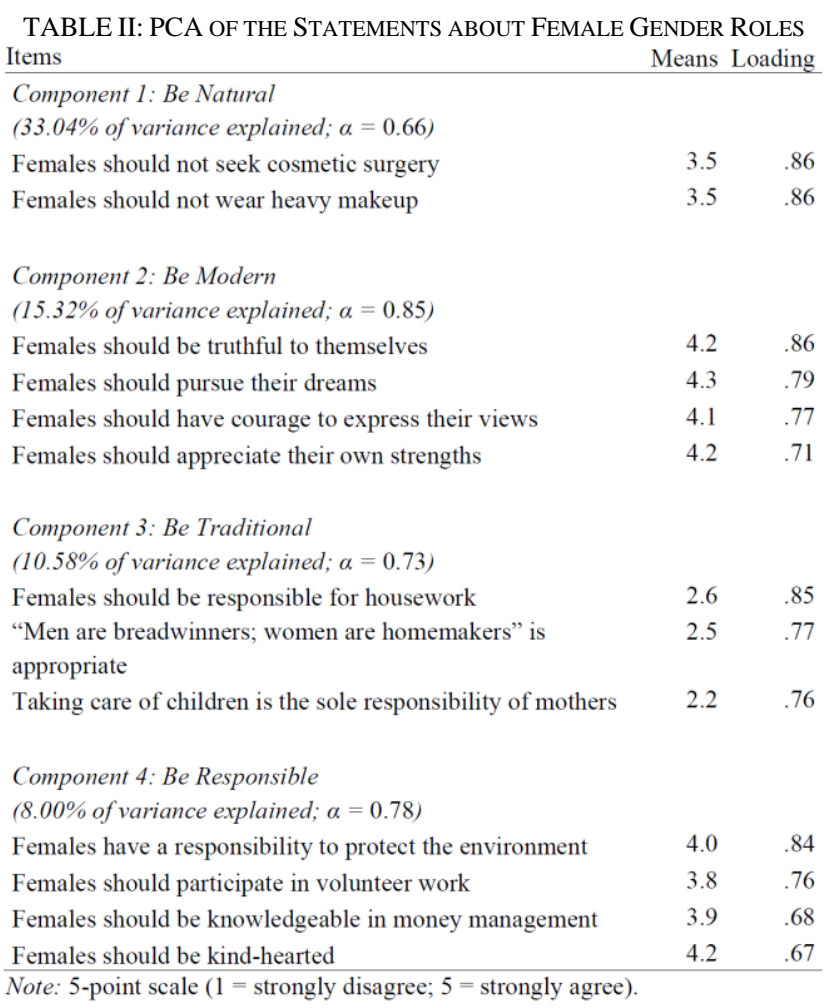

\section{Hypothesis Testing}

To assess the importance of each independent variable, especially the importance of differentiating adolescents' liminal stages when predicting their brand evaluations, a multiple-step regression model was employed. The model also aimed to test the two groups of hypotheses; that is, whether the independent variables have an impact on the dependent variables (H1a \& b), whether survey location is less important when other predictors are taken into account (H2a \& b).

Four-step multiple regression was conducted with the teenage girls' evaluations of the "youth brands" and the "adult brands" as dependent variables. In each analysis the survey location was entered at step one of the regression, the liminal stage of adolescence was entered at step two, the two economic status variables (family income and housing status) came in at step three, and the four female identities at step four. The variance inflation factors (VIF) for each variable in the four analyses varied between 1 and 2, indicating that the assumption of no multicollinearity was met. 


\section{Impact on the Evaluations of Youth Brands}

Table III summarizes the results of the multiple-step regression predicting respondents' evaluations of youth brands. The regression revealed that the survey locations contributed significantly to the observed responses, $F$ (1, $517)=3.758, p \leq 0.05$. But that variable accounted for only $0.7 \%$ of the variation in the teenage girls' evaluations of the youth brands. Introducing the three other predicting variables to the model step by step, the variance explained increased significantly at each step, indicating that all four variables had an impact on the dependent variable. In other words, the respondents' evaluations of the "youth brands" were influenced by the cultural differences between the two cities, the liminal stages of adolescence, their families' economic status, and their perceptions of gender roles. Therefore, H1a was supported.

TABLE III: MULTIPLE-STEP REGRESSION ANALYSIS PREDICTING RESPONDENTS' EVALUATIONS OF YOUTH BRANDS

\begin{tabular}{|c|c|c|c|c|}
\hline & Step $1-\beta$ & Step $2-\beta$ & Step $3-\beta$ & Step $4-\beta$ \\
\hline \multicolumn{5}{|l|}{ Locations } \\
\hline Hong Kong or Shanghai & $0.09^{*}$ & 0.07 & 0.05 & 0.05 \\
\hline \multicolumn{5}{|l|}{ Liminal stages } \\
\hline Younger or Older teens & & $-0.14 * *$ & $-0.15^{* * *}$ & $-0.15^{* * *}$ \\
\hline \multicolumn{5}{|l|}{ Economic status } \\
\hline Family income & & & $0.09^{*}$ & $0.10^{*}$ \\
\hline Housing status & & & 0.06 & 0.05 \\
\hline \multicolumn{5}{|c|}{ Perceptions of female identities } \\
\hline Be Natural & & & & -0.06 \\
\hline Be Modern & & & & 0.03 \\
\hline Be Traditional & & & & $0.13^{* *}$ \\
\hline Be Responsible & & & & 0.07 \\
\hline Variance explained $\left(\mathrm{R}^{2}\right)$ & $0.01^{*}$ & $0.03^{* * *}$ & $0.04 * * *$ & $0.06^{* * *}$ \\
\hline$\Delta \mathrm{R}^{2}$ & $0.01^{*}$ & $0.02^{* *}$ & $0.01^{*}$ & $0.02^{*}$ \\
\hline
\end{tabular}

a. Locations: Hong Kong $=0$, Shanghai $=1$

b. Liminal stages: Younger teens $=1$, Older teens $=2$

c. Family income: Low $=1$, Middle $=2$, High $=3$

d. Housing status: Rental $=1$, Owned $=2$

${ }^{*} p<.05, * * p<.01, * * * p<.001$

$\mathrm{N}=519$.

Starting from Step 2, when the liminal stage of adolescence was added as a predictor, the beta weight of survey location became non-significant. The importance of survey location remained non-significant during the next two steps of the analysis. This means that importance of location as a predictor of the respondents' evaluations of youth brands declined immediately as soon as other factors, especially the liminal stage of adolescence, were taken into account. Therefore, H2a was supported.

\section{E. Impact on the Evaluations of Adult Brands}

Table IV summarizes the results of the multiple-step regression predicting respondents' evaluations of adult brands. The four-step multiple regression revealed that the survey location contributed significantly to the first three regression models and accounted for $1.7 \%$ of the variation in the first stage. Adding the other three predicting variables increased the variance explained significantly at each step, which indicates that all four variables had an impact on the dependent variable. Therefore, H1b was supported.
TABLE IV: MULTIPLE-STEP REGRESSION ANALYSIS PREDICTING RESPONDENTS' EVALUATIONS OF ADULT BRANDS

\begin{tabular}{|c|c|c|c|c|}
\hline & Step $1-\beta$ & Step $2-\beta$ & Step $3-\beta$ & Step $4-\beta$ \\
\hline \multicolumn{5}{|l|}{ Locations } \\
\hline Hong Kong or Shanghai & $0.13^{* * *}$ & $0.11 *$ & $0.11^{*}$ & 0.08 \\
\hline \multicolumn{5}{|l|}{ Liminal stages } \\
\hline Younger or Older teens & & $-0.14^{* *}$ & $-0.15^{* * *}$ & $-0.15^{* * *}$ \\
\hline \multicolumn{5}{|l|}{ Economic status } \\
\hline Family income & & & $0.13^{* *}$ & $0.14^{* *}$ \\
\hline Housing status & & & 0.01 & 0.01 \\
\hline \multicolumn{5}{|l|}{ Perceptions of female identities } \\
\hline Be Natural & & & & -0.03 \\
\hline Be Modern & & & & 0.02 \\
\hline Be Traditional & & & & 0.09 \\
\hline Be Responsible & & & & $0.17^{* *}$ \\
\hline Variance explained $\left(\mathrm{R}^{2}\right)$ & $0.02 * *$ & $0.04^{* * * *}$ & $0.05^{* * *}$ & $0.09^{* * *}$ \\
\hline$\Delta \mathrm{R}^{2}$ & $0.02^{* * *}$ & $0.02 * *$ & $0.02 * *$ & $0.03^{* * * *}$ \\
\hline \multicolumn{5}{|l|}{ Notes: } \\
\hline \multicolumn{5}{|c|}{$\begin{array}{l}\text { a. Locations: Hong Kong }=0 \text {, Shanghai }=1 \\
\text { b. Liminal stages: } \text { Younger teens }=1, \text { Older teens }=2 \\
\text { c. Family income: } \text { Low }=1, \text { Middle }=2, \text { High }=3 \\
\text { d. Housing status: Rental }=1, \text { Owned }=2\end{array}$} \\
\hline \multicolumn{5}{|l|}{${ }^{*} p<.05,{ }^{* *} p<.01,{ }^{* * *} p<.001$} \\
\hline $\mathrm{N}=518$ & & & & \\
\hline
\end{tabular}

At step 2 and 3, introducing the variable of liminal stages of adolescence to the model did not immediately eliminate the significance of location, though location had the smallest beta weight among the significant predictors. Only at step 4 did survey location lose its predictive power and become non-significant. Therefore, $\mathrm{H} 2 \mathrm{~b}$ was supported.

Overall, the liminal stage of adolescence apparently was one of the most important predictors. At step 2, that variable accounted for an additional $1.9 \%$ of the variance in brand evaluations, and the change in $R^{2}$ was significant, $F(2,515)$ $=9.487, p \leq 0.001$. At steps 2 and 3 the beta weight of the liminal stage variable exceeded that of all the other predictors, indicating its independent contribution to the variance in the respondents' evaluations of adult brands over and above other predictors.

\section{DISCUSSION}

This study had two main objectives. Theoretically, it was designed to test the importance of adolescents' stages of liminality in influencing their roles as consumers. The predictive power of the liminal stage of adolescents was compared with those of other cultural, economic and psychographic factors in predicting brand evaluations. The results of the hypothesis testing supported the argument that liminal stage (proxied by year in school) is a powerful predictor.

Due to cultural differences, girls from Hong Kong and Shanghai would be expected to have different evaluations of the six global brands no matter whether they are marketed to children or the adults. And this was indeed evident in the data. However, such geographical variations should not be regarded as absolute. As soon as the factor of liminal life stages was taken into account, geographical differences became much less important or even disappeared. The data show that when assessing global brands, middle school girls differ more significantly from their seniors in high school than from their contemporaries in another city. Hence, cross-cultural differences in brand evaluation can be offset 
by the differences associated with cross liminal stages of lives. What is more, in most conditions the predictive power of the liminal stage of adolescence surpassed even that of economic status and perceived gender identity, both of which are often thought of as very critical determinants of brand evaluations [34]. The question is, why?

There are several possible explanations. It is well understood that when children grow older they become more sensitive towards brands and process brand information in more sophisticated ways. For example, [35] discovered that while children 12 or older may associate brands with symbolic meanings such as prestige and success, younger children simply use the brand to identify a certain product or product category. [36] further revealed that symbolic consumption based on branding begins in early adolescence (age 12 or 13) and is accompanied by increasing materialism. Materialism then declines again in late adolescence (age 16 to 18). This may explain why the younger and the older teens in both cities showed such a significant differences in their brand evaluations, and even why the difference was negatively associated with age (i.e., the older teens showed less fondness for both child and the adult brands than the younger teens in both cities).

Second, age is considered an important determinant in marketing research, but "chronological age itself is an 'empty' variable" [1]. The importance of age is located in the things that it indexes, such as the degree of cognitive maturation. At the same time, Marcia [30] has pointed out that "One difficulty in studying adolescence is the definition of the period itself". Conventionally, "teenager" refers to ages 13 to 19, a broad span of seven years. But the significant cognitive, psychological, and physical changes during this period indicate the importance of differentiating stages of adolescence [37]-[39]. Therefore, we propose to use the concept of liminality as a crucial theoretical lens for such differentiations.

Liminality signifies the continuously transitional status of human life. The teenage years are usually regarded as a transitional stage from childhood to adulthood, but the individual variation in the rate of change along biological, social, or psychological dimensions within the seven years should not be overlooked. Adolescence should not be viewed as a homogenous period of time, but the lack of precision in the typical early, middle or late categorization makes it less useful than it could be. It is probably more useful to define several liminal stages which take in crucial turning points for identity construction, such as schooling, the family's situation, illness, etc. This study focused on schooling because in many societies the beginning of adolescence coincides with the start of secondary education [40]. During the transition into adolescence, teenagers increasingly spend more time with their peers than with their parents, and thus the parents' influence on adolescent behavior and development becomes less significant [41]. However, not only does adolescents' susceptibility to peer influence vary according to age [42], the peer culture and the pressure it exerts can be rather different between middle school and the high school [38]. That is one of the reasons why year in school (a proxy for liminal stage of adolescence) showed such a strong and significant relationship with the respondents' evaluations of the brands.

It is tempting to speculate that the relatively weak significance of cross-cultural differences in predicting brand evaluations could reflect the homogenization of consumer culture in today's global society. As some scholars have pointed out, globalization has increased the commonality of consumer behavior across countries while reducing the homogeneity within countries [43]. The results of this study tend to support such assertions. Although Hong Kong and Shanghai have followed different paths in their social, economic, and cultural development, as world-class metropolitan cities, both of them have been acculturated by similar advertising content and practices through the marketing of international brands. Therefore it is not difficult to understand why the teenage girls' evaluations of the six global brands varied more within than between the two cities.

This suggests that we need to re-think the unit of analysis in consumer research. Almost two decades ago, [44] argued that consumer segments worldwide can be identified through applying "a common ethos" regardless of their native cultures.

At the same time, the limitations associated with this research should not be overlooked. First, the utility of the findings is limited by the non-randomized sampling process. Second, the two cities under examination were both Chinese cosmopolitan cities. Future research might fruitfully sample more culturally distant populations. In addition, the operationalization of the concept of liminality could be further developed. A longitudinal cohort study might be more effective for this purpose. Finally, future research might study richer dependent variables that might more effectively exhibit the conceptual power of liminality.

\section{CONCLUSION}

A study was conducted to introduce the concept of liminality and examine its impact on adolescent girls' brand evaluation. The results of this study suggest that in today's era of globalization, individuals, rather than countries or regions, should be regarded as the unit of analysis for consumer studies.

\section{REFERENCES}

[1] R. A. Settersten and K. U. Mayer, "The measurement of age, age structuring, and the life course," Annual Review of Sociology, vol. 23, no. 1, pp. 233-261, 1997.

[2] A. V. Gennep, The Rites of Passage, London, UK: Routledge \& Paul, 1960.

[3] J. J. Arnett, "Emerging adulthood: A theory of development from the late teens through the twenties," American Psychologist, vol. 55, no. 5, pp. 469-480, May 2000.

[4] J. J. Arnett, Emerging Adulthood: the Winding Road from the Late Teens through the Twenties, New York, NY: Oxford University Press, 2004.

[5] L. K. George, "Sociological perspectives on life transitions," Annual Review of Sociology, vol. 19, no. 1, pp. 353-373, Jan. 1993.

[6] V. W. Turner, The Forest of Symbols: Aspects of Ndembu Ritual, Ithaca, NY: Cornell University Press, 1967.

[7] V. W. Turner, "Betwixt and between: The liminal period in rites of passage," in Betwixt \& Between: Patterns of Masculine and Feminine Initiation, L. C. Mahdi, S. Foster, and M. Little, Eds. La Salle, IL.: Open Court, 1987, pp. 3-19.

[8] C. H. Noble and B. A. Walker, "Exploring the relationships among liminal transitions, symbolic consumption, and the extended self," Psychology and Marketing, vol. 14, no. 1, pp. 29-47, Jan. 1997. 
[9] K. Keniston, Youth and Dissent: The Rise of a New Opposition, New York, NY: Harcourt Brace Jovanovich, 1971.

[10] D. R. John, "Consumer socialization of children: A retrospective look at twenty-five years of research," Journal of Consumer Research, vol. 26, no. 3, pp. 183-213, Dec. 1999.

[11] D. T. Cook, "Beyond either/or," Journal of Consumer Culture, vol. 4, no. 2, pp. 147-153, July 2004.

[12] K. Cody, "No longer, but not yet': Tweens and the mediating of threshold selves through liminal consumption," Journal of Consumer Culture, vol. 12, no. 1, pp. 41-65, Apr. 2012.

[13] K. Cody, K. Lawlor, and P. Maclaren, "No longer, but not yet: Tweens and the mediating of liminal selves through metaconsumption," in Advances in Consumer Research, D. W. Dahl, G. V. Johar et al., Eds. Duluth, MN: Assocition for Consumer Research, 2010.

[14] K. Cody, K. Lawlor, and P. Maclaren, "Threshold lives: Exploring the liminal consumption of tweens", in Advances in Consumer Research, M. C. Campbell, J. Inman, and R. Pieters, Eds. Duluth, MN: Association for Consumer Research, 2010.

[15] J. Kroger, Identity in Adolescence: The Balance between Self and Other, London, UK; New York, NY: Routledge, 2004.

[16] D. T. Cook and S. B. Kaiser, "Betwixt and between," Journal of Consumer Culture, vol. 4, no. 2, pp. 203-227, July 2004.

[17] L. N. Chaplin and D. R. John, "The development of self-brand connections in children and adolescents," Journal of Consumer Research, vol. 32, no. 1, pp. 119-129, Jun. 2005.

[18] A. M. J. Muniz and T. C. O'Guinn, "Brand community," Journal of Consumer Research, vol. 27, no. 4, pp. 412-432, Mar. 2001.

[19] R. Elliott and K. Wattanasuwan, "Brands as symbolic resources for the construction of identity," International Journal of Advertising, vol. 17, no. 2, pp. 131-144, Apr. 1998.

[20] G. D. McCracken, "The value of the brand: An anthropological perspective," in Brand Equity \& Advertising: Advertising's Role in Building Strong Brands, D. A. Aaker and A. L. Biel, Eds. Hillsdale, N.J.: Lawrence Erlbaum Associates, 1993, pp. 125-139.

[21] G. D. McCracken, Culture and Consumption II : Markets, Meaning, and Brand Management, Bloomington, IN: Indiana University Press, 2005.

[22] G. P. Moschis and R. L. Moore, "Decision making among the young: A socialization perspective," Journal of Consumer Research, vol. 6, no. 2 , pp. 101-112, Sep. 1979.

[23] S. Ward, "Consumer socialization," Journal of Consumer Research, vol. 1, no. 2, pp. 1-14, Sep. 1974.

[24] A. R. Kamaruddin and S. Mokhlis, "Consumer socialization, social structural factors and decision-making styles: A case study of adolescents in Malaysia," International Journal of Consumer Studies, vol. 27, no. 2, pp. 145-156, Mar. 2003.

[25] M. B. Holbrook and R. M. Schindler, "Age, sex, and attitude toward the past as predictors of consumers' aesthetic tastes for cultural products," Journal of Marketing Research, vol. 31, no. 3, pp. 412-422, Aug. 1994

[26] E. W. Y. Lee, "Introduction: Gender and change in Hong Kong," in Gender and Change in Hong Kong: Globalization, Postcolonialism, and Chinese Patriarchy, E. W. Y. Lee, Ed. Hong Kong: Hong Kong University Press, 2003, pp. 3-22.

[27] C. Li, "Rediscovering urban subcultures: The contrast between Shanghai and Beijing," The China Journal, vol. 36, pp. 139-153, July 1996.

[28] R. W. M. Wong, "The story of Hong Kong: Review of her infrastructure developments and strategies to meet a sustainable future," presented at XXII IAHS World Congress on Housing: Sustainability of the Housing Projects, Trento, Italy, September 21-25, 2004.

[29] L. Y. Zhang, "Economic development in Shanghai and the role of the state," Urban Studies, vol. 40, no. 8, pp. 1549-1572, July 2003.
[30] J. E. Marcia, "Identity in adolescence," in Handbook of Adolescent Psychology, A. J. Adelson, Ed. New York: Wiley, 1980, pp. 159-187.

[31] K. Chan and R. B. Williams, "Adolescent girls' perception of gender roles and gender identities: A qualitative study," Working paper, 2012.

[32] E. S. Moore and V. J. Rideout, "The online marketing of food to children: Is it just fun and games?" Journal of Public Policy \& Marketing, vol. 26, no. 2, pp. 202-220, Fall 2007.

[33] Interbrand. (2011). 2011 ranking of the top 100 brands. [Online]. Available: http://www.interbrand.com/en/best-global-brands/best-global-brands2008/best-global-brands-2011.aspx

[34] M. S. Roth, "The effects of culture and socioeconomics on the performance of global brand image strategies," Journal of Marketing Research, vol. 32, no. 2, pp. 163-175, May 1995.

[35] G. B. Achenreiner and D. R. John, "The meaning of brand names to children: A developmental investigation," Journal of Consumer Psychology, vol. 13, no. 3, pp. 205-219, Oct. 2003.

[36] L. N. Chaplin and D. R. John, "Growing up in a material world: Age differences in materialism in children and adolescents," Journal of Consumer Research, vol. 34, no. 4, pp. 480-493, Dec. 2007.

[37] A. Wigfield, J. S. Eccles, D. M. Iver, D. A. Reuman, and C. Midgley, "Transitions during early adolescence: Changes in children's domain-specific self-perceptions and general self-esteem across the transition to junior high school," Developmental Psychology, vol. 27, no. 4, pp. 552-565, Dec. 1991

[38] D. A. Kinney, "From nerds to normals: The recovery of identity among adolescents from middle school to high school," Sociology of Education, vol. 66, no. 1, pp. 21-40, Jan. 1993.

[39] M. F. Ji, "Child-brand relations: A conceptual framework," Journal of Marketing Management, vol. 24, no. 5-6, pp. 603-619, July 2008.

[40] B. A. Levinson, "'Una etapa siempre difícil': Concepts of adolescence and secondary education in mexico," Comparative Education Review, vol. 43, no. 2, pp. 129-161, May 1999.

[41] J. R. Harris, "Where is the child's environment? A group socialization theory of development," Psychological Review, vol. 102, no. 3, pp. 458-489, July 1995.

[42] B. B. Brown, "Peer groups and peer cultures," in At the Threshold: The Developing Adolescent, S. S. Feldman and G. R. Elliott, Eds. Cambridge: Harvard University Press, 1990, pp. 171-196.

[43] M. Cleveland and M. Laroche, "Acculturation to the global consumer culture: Scale development and research paradigm," Journal of Business Research, vol. 60, no. 3, pp. 249-259, 2007.

[44] T. J. Domzal and J. B. Kernan, "Mirror, mirror: Some postmodern reflections on global advertising," Journal of Advertising, vol. 22, no. 4, pp. 1-20, Dec. 1993.

Dong Dong is a research assistant professor at the David C. Lam Institute for East-West Studies, Hong Kong Baptist University. She received her PhD in mass communication from the University of Minnesota, Twin Cities. Her main research interests include international communication, health communication and media sociology.

Kara Chan is a professor at the Department of Communication Studies at the Hong Kong Baptist University. She worked in advertising and public relations profession and as a statistician for the Hong Kong Government. She is the author of over 120 articles and book chapters on advertising, consumer behavior, and media effects. She was a Fulbright scholar at Bradley University, Illinois for 1999 to 2000. She co-authored Advertising to Children in China (Chinese University Press, 2004) with Professor James U. McNeal and authored Youth and Consumption (City University of Hong Kong Press, 2010). 